\title{
Hacia una política de la ininteligibilidad: sobre la representación de la transexualidad enTranslúcid@de Elena Guiochins
}

María Teresa Vera-Rojas

Universitat de Lleida

El 9 de marzo de 2012, una activista transgénero mexicana, Agnes Torres Hernández, fue asesinada por cinco hombres en la ciudad de Chipilo, en el estado de Puebla. Aunque se quiso alegar como motivo del asesinato el intento de robo de su coche, Agnes fue asesinada por su pareja, Jorge Flores, cuando esta le confesó que era transgénero. Según las noticias que cubrieron el hecho, Flores comenzó a golpearla y, al escuchar los gritos, los otros hombres que lo acompańaban entraron a la casa y siguieron pegándole, la degollaron, la quemaron y después tiraron su cuerpo. Uno de los asesinos era menor de edad y salió en libertad en 2015. A otros tres les fue dictada sentencia en 2016; el quinto, Jorge Flores, todavía sigue prófugo de la justicia.

A cuatro ańos del asesinato de Agnes Torres, el 31 de marzo de 2016, la dramaturga mexicana, Elena Guiochins, lleva a escena Translúcid@, una obra que parte de la denuncia ante este asesinato pero cuyo argumento se expande gracias a un exhaustivo trabajo de investigación en torno a la sexualidad, la identidad de género y el cuerpo, por medio del cual se busca explorar "incertidumbres humanas relativas a la sexualidad", así como también proponer "una reflexión filosófica y espiritual sobre la identidad en relación a la idea que tenemos del Yo y nuestro cuerpo" ${ }^{1}$. En este sentido, Guiochins se posiciona desde un lugar humanista que piensa las representaciones de la transexualidad como una

1. Elena Guiochins, “Translúcid@”, Lectora, 22 (2016), p. 252. 
manera de preguntarse acerca de los discursos que conciben, regulan y normalizan los sujetos, las identidades y las vidas que se corresponden con lo humanamente inteligible ${ }^{2}$, es decir, en este contexto, "ser humano, dentro de la modernidad eurocéntrica, supone ser legiblemente identificado con género masculino o femenino, de una forma que se desvanece dentro de la neblina ideológica a la que llamamos Naturaleza”3.

Es por esta intención humanista que en esta obra la identidad trans no se presenta como un cuestionamiento de las categorías normativas y los cuerpos inteligibles hombre y mujer. Es decir, en Translúcid@ no existe un deliberado esfuerzo por romper paradigmas o problematizar los límites genéricos del cuerpo trans, sino que busca inscribir la transexualidad y sus sujetos en el marco del humanismo y, consecuentemente, de normalizar el passing $g^{4}$ de sus personajes en el contexto de referentes normativos de feminidad. En palabras de Guiochins:

Translúcid@ es una historia en torno al cuerpo y la vida de aquellos cuyo sexo biológico y psicológico no coinciden; mi obra reflexiona sobre el interrogante de la transexualidad donde el cambio de sexo no implica un cambio en la naturaleza esencial del individuo sino en la percepción de los otros hacia su persona y las consecuencias que este hecho implica. [...] Mientras más profundamente sean comprendidos y se vivan nuevas actitudes, más íntima, satisfactoria y noble se volverá la interacción entre los seres humanos. Me interesa ofrecer al público una obra que reflexione sobre el interrogante de la transexualidad en el mundo contemporáneo y también ofrecer nuevas

2. La comprensión de la sexualidad humana estaría determinada entonces por las regulaciones que la norma ejerce a favor de unos sujetos encarnados y a costa de la exclusión y de las violencias que se ejercen sobre otros; en palabras de Judith Butler: "la normatividad tiene un doble sentido. Por una parte se refiere a los propósitos y a las aspiraciones que nos guían, los preceptos por los cuales estamos obligados a actuar o hablar el uno al otro, las presuposiciones que se manifiestan habitualmente, mediante las cuales nos orientamos y que orientan nuestras acciones. Por otra parte, la normatividad se refiere al proceso de normalización, la forma en que ciertas normas, ideas e ideales dominan la vida incorporada (embodied) y proporcionan los criterios coercitivos que definen a los 'hombres' y a las 'mujeres' normales. Y en este segundo sentido, vemos que las normas son lo que rige la vida 'inteligible', a los hombres 'reales' y a las mujeres 'reales'. Pero cuando desafiamos estas normas no está claro si estamos todavía viviendo o deberíamos estarlo, si nuestras vidas son valiosas o si pueden convertirse en tales, si nuestros géneros son reales, o incluso si pueden verse como tales" (Judith Butler, "La cuestión de la transformación social", Deshacer el género, trad. Patrícia Soley-Beltran, Paidós, Barcelona, 2006, pp. 291-292).

3. Susan Stryker, "Prólogo", Políticas trans. Una antología de textos desde los estudios trans norteamericanos, eds. Pol Galofre y Miquel Missé, Egales, Barcelona-Madrid, 2015, p. 12.

4. De acuerdo con Sandy Stone, passing significa "vivir con éxito en el género que escogió, ser aceptada como miembro 'natural' de ese género"; pero, al mismo tiempo, "Pasar significa la negación de la mezcla. Pasar es lo mismo que borrar el rol de género anterior o la construcción de una historia plausible. Si tomamos en consideración que la mayoría de personas transexuales deciden llevar a cabo la reasignación cuando llegan a los treinta o cuarenta ańos, esto implica borrar una parte considerable de su experiencia personal. Mi contienda es que este proceso, en el cual tanto estas personas como el sistema médico legal y psicológico son cómplices, excluye la posibilidad de una vida basada en las posibilidades intertextuales de un cuerpo transexual" (Sandy Stone, "El imperio contraataca. Un manifiesto postransexual”, Politicas trans..., pp. 58-59). 
posibilidades de discernimiento en torno al cuerpo y la impunidad con la que son cometidos crímenes de odio5.

Con todo, una de las características distintivas de Translúcid@es la de partir de las experiencias de las mujeres trans para construir un texto que denuncia las diferentes formas de violencia transfóbica que existen en la sociedad mexicana, así como la falta de legislación que defienda los derechos civiles y legales de la comunidad trans. Asimismo,Translúcid@busca desautorizar los discursos que fijan una identidad de género a un cuerpo sexuado, así como los tipos que abogan por una masculinidad hegemónica y violenta, todo esto a diferencia de la tradición dramática en Occidente que, como demuestra Josep Maria Sala Valldaura al referirse al teatro breve español del siglo XVIII, ha buscado adoctrinar sobre el significado de la masculinidad mediante la ridiculización de tipos afeminados y extranjerizantes:

Ensayo moral, periodismo, teatro breve... toda clase de obras se van a suceder, sobre todo a partir de la década de los sesenta, en la caricatura de la petimetría y el cortejo. En realidad, los principios morales con que se abomina de tal práctica responden a criterios secularmente empleados para denunciar el pecado y el desorden. También la dramaturgia había ya ridiculizado en la misma dirección diversos tipos, figuras o figurones: a hidalgos vestidos estrafalariamente, a lindos y a gurruminos - muestras quizás algún día para quien se atreva a escribir una historia de la comicidad basada en la homofobia- Moreto, Cañizares y Zamora les deben una parte de su fama. La cadena, como ha señalado Mireille Coulon, es larga y prosigue en el siglo XIX: lindos, petimetres, lechuguinos, currutacos, gomosos y otros pisaverdes reúnen en sí mismos la afectación indumentaria, el afeminamiento, la frivolidad... ${ }^{6}$

A partir de estas consideraciones, me interesa explorar la apuesta performativa de Guiochins al hacer del binarismo y de la transición elementos estructurales para el desarrollo de la obra y la puesta en escena, pero también para la exploración de la identidad de género de los personajes y su efecto en el espectador. En relación con estas estrategias, quiero demostrar cómo, sin perder su potencial crítico, en Translúcid@ el cuerpo es enfatizado como la marca de inteligibilidad y supervivencia social que determina la identidad de género de los sujetos, a partir del énfasis en las vestimentas como expresión de la feminidad ${ }^{7}$. En consecuencia, e indisociable de lo anterior, quiero plantear cómo

5. Elena Guiochins, “Translúcid@”, p. 253.

6. Josep Maria Sala Valldaura, "Gurruminos, petimetres, abates y currutacos en el teatro breve del siglo XVIII”, Revista de Literatura, LXXI, 142 (2009), p. 435.

7. Esta observación dista de ser anecdótica porque la ropa no solo articula las diferencias de género, sino que, en palabras de Entwistle, "es uno de los ejemplos más inmediatos y efectos de la forma en las cuales el cuerpo es generado, esto es, hecho 'femenino' o 'masculino'" (Joanne Entwistle, The Fashioned Body: Fashion, Dress and Modern Theory, Polite, Cambridge, p. 141; la traducción es mía). 
en esta obra la masculinidad es representada como un correlato de la transexualidad y un refugio de la transfobia. Finalmente, y de la mano de Sandy Stone, me interesa pensar en qué medida la inteligibilidad cultural de los cuerpos trans a través del passing se convierte en un modo de normalización de los discursos tradicionales de género, en lugar de un modo de resignificación de la violencia que estos discursos ejercen en aquello que Judith Butler llamaba el orden obligatorio del sexo/cuerpo, género y deseo ${ }^{8}$.

Translúcid@es una suerte de obra coral que representa diferentes aristas de las regulaciones que afectan a los sujetos trans. Su argumento principal se erige en torno a las experiencias, por una parte, de Agnes, psicóloga transexual, maltratada y, finalmente, asesinada por su pareja, Adrián; y, por otra, de Adriano/Adei, un médico, esposo y padre de familia a quien conocemos en medio de una discusión en la que confiesa a su esposa su decisión definitiva de habitar su identidad y cuerpo transgéneros. Junto a ellos, Adela, la esposa de Adriano y su hija, Adriana, encarnan la experiencia familiar y las dificultades en la comprensión de las identidades trans en el espacio privado. Nicté y Adorno, amigas prostitutas de Agnes, aun cuando refuerzan el recurrente estereotipo de la transexualidad asociado a la prostitución, representan las formas de comunidad alternativas de solidaridad y apoyo que se construyen entre los sujetos trans en el espacio público. A partir de estas dualidades se presentan los personajes en el texto:

\section{PERSONAJES:}

1. ADRIANO: Esposo de Adela, también Adei.

ADEI: Médico cirujano travesti.

2. ADELA: Esposa de Adriano, también Agnes. AGNES: Psicóloga transexual.

3. ADRIANA: Hija de Adriano y Adela, también Ariadna. ARIADNA: Prostituta.

4. ADORNO: Adolescente travesti, también Adrián.

ADRIÁN: Homicida.

5. NICTÉ: Sexo-servidor transexual.

Es indispensable que los personajes indicados en el reparto sean interpretados por un mismo actor. El elenco consta de cinco actores.

La obra no pretende reproducir hechos y/o acontecimientos históricos en un marco lineal'.

La arquitectura de esta obra evidencia un arduo trabajo conceptual, en el que las acotaciones adquieren un papel imprescindible para configurar la intención programática de su autora, porque, desde la misma presentación de los personajes hasta las indica-

8. Véase Judith Butler, Gender Trouble: Feminism and the Subversion of Identity, Routledge, New York-London, 1990.

9. Elena Guiochins, “Translúcid@”, p. 255. 
ciones en los cambios de escenas, en Translúcid@ impera una conciencia teórica de las aproximaciones desde las que se concibe la identidad como un proceso de transición, tal como ilustran las siguientes escenas:

Transición. ADELA se transforma en AGNES.

AGNES: ¿Te gustan los hombres?

ADEI: Estoy explorando. Siempre he sido una rebelde que todo lo cuestiona. Pero también requiero la base del sentir. ¡Necesito sentir!

AGNES: Te has preguntado alguna vez: ¿qué nos hace sentirnos hombres o mujeres?

ADEI: ¿No basta la anatomía?

AGNES: No, no basta. La sexualidad es subjetiva. Cada quien tiene una idea de lo que es un hombre y una mujer. Una vez mi abuela me dijo: - ¡Tú deberías de casarte y ya! Si tienes tus "cosas" deberías de tenerlas en lo oscurito. Mi abuela lo dijo con muy buena intención, pero eso fue terrible.

ADEI: ¿Qué tan terrible?

AGNES: Unas cuantas golpizas, muchos años de terapia, el rechazo de la humanidad, en fin. Tú sabes de lo que hablo.

ADEI: Empiezo a saberlo. Me gusta esta vida pero también me duele.

AGNES: Eres novata. Tienes que curtirte la piel para que todo se te resbale.

ADEI: ¿Y por qué tengo yo, hombre heterosexual, profesionista y padre de familia moderadamente conforme con la vida, por qué tengo que rebelarme así?

AGNES: Tal vez lo que te perturba es que la sexualidad, los roles y la identidad no sean inamovibles ${ }^{10}$.

Y es que, más allá de la correspondencia de cada personaje con diferentes universos en los que se mueven los sujetos trans, lo interesante de esta propuesta está en su modo de representación: cuatro de los cinco actores encarnan dos personajes cada uno, y el cambio de personajes se produce mediante un efecto de "transición", según el cual se transforman de un modo de ser a otro en cada escena y dan sentido a la particularidad de su título ${ }^{11}$.

Esta movilidad dialoga con lo que Halberstam entiende como la fantasía que tiene el cine de exponer "[l] a potencialidad [que tiene el] cuerpo para morfosearse, mudarse, cambiar y convertirse en fluido" ${ }^{12}$, una movilidad que busca contribuir a la idea de flexibilidad que puede convocar el cuerpo transgenérico. A su vez, la idea de presentar en escenas a personajes que se desdoblan en otros personajes permite representar el carácter performativo de la identidad, así como desautomatizar la asignación normativa de una identidad de género a un cuerpo sexuado y una inclinación sexual determinados.

10. Ibid., p. 264.

11. En su definición normativa, el Diccionario de la Real Academia denomina "Translúcido" a un cuerpo "Que deja pasar la luz, pero que no deja ver nítidamente los objetos".

12. Judith Halberstam, "La mirada transgenérica", trad. Meri Torras, Lectora, 10 (2004), p. 49. 
Además de este recurso de transición, los diálogos y acotaciones funcionan como registros formales que apuntan hacia la "verdad del sexo"13 mediante discursos que regulan las formas de sujeción e identificación de los personajes con su cuerpo y su sexualidad. Los diálogos en los que los personajes exponen su proceso de tránsito, el rechazo a su sexo biológico así como a la identidad de género asignada, la exploración del deseo o las formas de violencia transfóbicas sufridas forman parte de una miríada de confesiones que no solo están dirigidas a sí mismos, sino que se producen para otros — los espectadores- quienes se ven obligados a interrogar su mirada, pero también a preguntarse por su propia identidad, "sobre la consistencia, la estabilidad, la congruencia de su propio yo, sobre el carácter sustancial de su subjetividad y sexualidad" 14 . Es en este sentido que cobra mayor significación la afirmación de Judith Butler cuando señala que "El acto de informar sobre uno mismo y el acto de autoobservación tienen lugar en relación con cierta audiencia, hay una cierta audiencia que es el destinatario imaginario; estos actos se dan ante una cierta audiencia, para la cual se produce una imagen verbal y visual del yo"15. De esta forma, en Translúcid@la performance, la confesión y la mirada confluyen en los significados atribuidos al cuerpo trans y en las formas de subjetivación que regulan los discursos acerca de la sexualidad.

A estos significados contribuyen diferentes elementos en la obra, desde la inscripción de la medicina en la lectura y exploración del cuerpo de mano del personaje de Adriano, pero también de parte de Agnes, quien hace las veces de psicóloga y consejera de la comunidad trans, pasando por el activismo y la representación de la visibilidad trans en los cabarets, las calles y las luchas por los derechos civiles, y sigue de manera no menos significativa con la importancia del nombre, no solo porque llamarse a sí mismo es un acto de empoderamiento, especialmente en el caso de minorías que han sido catalogadas y marcadas como otros por sujetos hegemónicos, sino porque, además, el nombre de los personajes define su personalidad y nos orienta en el desarrollo de las acciones, especialmente de cara a quienes nos miran y demandan la coherencia del cuerpo y la verdad del sexo en el nombre:

Consultorio de AGNES.

AGNES: Mi nombre es de origen griego, hace referencia al cordero de Dios. Se le representa con un cordero por la similitud de este nombre con la palabra latina "agnus", que designaba el cordero del sacrificio.

ADEI: Es un nombre fuerte.

AGNES: Hay nombres que llaman al corazón.

13. Véase Michel Foucault, Historia de la sexualidad. 1. La voluntad del saber, trad. Ulises Guińazú, Siglo XXI, Madrid, 2006, pp. 53-77.

14. Annalisa Mirizio, "Del carnaval al drag: la extrańa relación entre masculinidad y travestismo", Nuevas masculinidades, eds. Marta Segarra y Àngels Carabí, Icaria, Barcelona, p. 144.

15. Judith Butler, "Hacerle justicia a alguien: la reasignación de sexo y las alegorías de la transexualidad", Deshacer el género, p. 103. 
ADEI: Es difícil analizar mi propia vida y ser honesto. Duele.

AGNES: La sexualidad no la eliges en catálogo, la descubres. A veces con mucha sorpresa, pero no la eliges: la descubres.

ADEI: Siempre hubo algo en mí que no sabía definir bien.

AGNES: ¿Quién es Adei?

ADEI: Yo sólo soy reina en mi planeta y punto.

AGNES: ¿De dónde salió ese nombre tan original, Adei?

ADEI: Yo lo inventé y luego descubrí que quería decir muchas cosas.

AGNES: ¿Qué cosas?

ADEI: En la raíz latina significa "sin Dios" pero también quiere decir "hacia Dios". Para mí es un anagrama de "idea”.

AGNES: Me gusta mucho tu nombre.

ADEI: A mí el tuyo.

AGNES: A la gente le fascinan esos seres que parecemos contenerlo todo ${ }^{16}$.

Aunque Agnes y Adei son nombres que, efectivamente, desafían la insistencia en reconocer la identidad de género a través del nombre, la obra presenta esta doble lectura: por un lado, apuesta por la dualidad y la movilidad identitarias, pero, por otro, insiste en registrar la humanidad de los sujetos trans mediante la inteligibilidad de sus cuerpos. Es por esto último que, en Translúcid@, la idea de movilidad se torna, por momentos, problemática. En ocasiones, los diálogos nos invitan a pensar en el cuerpo como una materia que puede definirse más allá de la violencia textual inscrita en el cuerpo transexual ${ }^{17}$ :

NICTÉ: A pesar de la tortura y el dolor, el cuerpo de mi amiga siempre fue bello. Me pregunto si la belleza existe sólo cuando el Yo ya no está. ¿Cómo nombrar este cuerpo que yace aquí frente a nosotros? Si observáramos la piel, ¿podríamos descubrir la ruta de vida de este ser humano? El yo, la persona, el nombre, la identidad, la forma, todas esas palabras. Detrás de la palabra Yo, ¿quién es quién ${ }^{318}$

Sin embargo, en buena parte de la obra, esta movilidad se encuentra con la normatividad al identificar el cuerpo trans a partir de identidades de género que se reconocen en el marco del dimorfismo sexual, especialmente mediante el énfasis en la apariencia y la vestimenta como elementos distintivos de la feminidad:

NICTÉ: Entré en el mundo de la prostitución y luego supe. En primer lugar, mi ego tenía necesidad de sentir esa capacidad de seducción sobre los hombres. Ese sentirse mujer deseable. Te pones una minifalda, te pones bonita, te paras en la esquina y ya estuvo. Parece que fue ayer cuando salí a la calle por primera vez, se me elevó la autoestima de golpe.

16. Elena Guiochins, “Translúcid@”, p. 259.

17. Sandy Stone, "El imperio contraataca. Un manifiesto postransexual”, p. 55.

18. Elena Guiochins, “Translúcid@”, p. 281. 
$[\ldots]$

ADELA: Aunque te vistas así, nunca serás una mujer.

ADEI: Una parte de mí lo es.

ADELA: ¿Eso crees?

ADEI: Soy mucho más que un hombre que se viste de mujer.

ADELA: Desde mi referencia, nunca serás una mujer.

ADEI: Tú no me puedes negar mi experiencia de ser mujer ${ }^{19}$.

$[\ldots]$

NICTÉ: Me empecé a dejar crecer el cabello, a dejar crecer las uñas. Fue paulatino: de las camisas a las camisetas y luego a las blusas; de los pantalones a los shorts y luego a las faldas; de los zapatos a los guaraches y luego a las zapatillas.

AGNES: Entre unos zapatos y unas zapatillas, no hay puntos intermedios. Entre unos pantalones y una falda, no hay puntos intermedios.

NICTÉ: Era esa búsqueda de quién era yo, de qué era. Tratando de encontrar mi identidad $^{20}$.

El hecho de hacer alusión al proceso de transición hacia una feminidad estereotipada, en lugar de desarticular conceptos normativos de feminidad y heterosexualidad, inscribe a las mujeres trans en una encrucijada, como seńala Julia Serano, quien en su estudio de las representaciones de las mujeres trans en los medios de comunicación explica cómo: "A las mujeres trans se les pide, por un lado, demostrar su feminidad mediante recursos superficiales, y, por otro, se les niega la condición de mujeres 'reales' debido a esta artificialidad. Después de todo, la masculinidad se define generalmente según la forma en que un hombre se comporta, mientras que la feminidad se define según la forma en que una mujer se presenta a sí misma" ${ }^{21}$. En este sentido, la sexualización de la feminidad, que el imaginario mediático y la sociedad de consumo producen en torno a las mujeres trans, fomenta no solo la normalización de la feminidad a partir del consumo y el cultivo de la apariencia ${ }^{22}$, sino que además contribuye a la regularización de una representación

19. Ibid., p. 262.

20. Ibid., p. 277.

21. Julia Serano, "Cazadores de faldas: por qué los medios de comunicación representan la revolución trans con pintalabio y tacones", Políticas trans..., p. 216.

22. La importancia del vestuario como un marcador genérico no solo responde a las tecnologías de producción y reproducción de los géneros en la sociedad, sino que además ha sido un recurso de diferenciación nacional, sexual y de clase en la tradición dramatúrgica; tal como apunta Sala Valldaura al referirse al teatro breve español del siglo XVIII: "Desde Ramón de la Cruz y a lo largo de toda la centuria, el petimetre y, con él, el abate lo ponen de relieve en el escenario del teatro breve saliendo vestidos ridículamente y de manera muy ceñida, sin 'sobriedad' masculina, a veces anunciándose por el ruido que el entrechocar de sus joyas y relojes provoca. Con verlos, el público puede menospreciarlos también por su peinado, su maquillaje, su barba rasurada, su corto espadín, su forma de andar o brincar, pues a menudo dan grotescos saltitos pese a su edad provecta. Hacen cortesías a la francesa y monerías y, en su excesiva 'finura', melindrean y hasta algunos afectan damerías y dengues. Cuchichean y murmuran mujerilmente, hablan de manera pedante y artificiosa de temas tan femeninos como la moda, carecen de entendimiento y esfuerzo intelectual. Ignoran 
normativa de la masculinidad como productiva y activa, esto es, una "subjetividad masculina hegemónica", la cual se conforma en torno a la idea de que "ser varón es poseer una masculinidad racional autosuficiente y defensiva-controladora que se define contra y a costa del otr@, dentro de una jerarquía masculina y con la mujer como sujeto en menos, generando además una lógica dicotómica del uno u otro, del todo o nada (donde la diversidad y los matices no existen)"23.

Pero no es solo por el énfasis en el carácter dicotómicos de las identidades de género queTranslúcid@atiende a la construcción de la masculinidad. De hecho, aun cuando esta no sea su intención principal, en Translúcid@la masculinidad —y no solo la feminidad - se convierte en correlato de la transexualidad femenina y se expresa a partir de diferentes escenarios en los que la supuesta pérdida de la hegemonía masculina de manos de la mujer trans "legitima" su ridiculización y minusvalía ${ }^{24}$. De esta forma nos encontramos con el escenario familiar, en el que el reconocimiento de la identidad transgénero de parte del personaje Adriano/Adei desestabiliza la armonía familiar, no solo porque quiebra el paradigma heteronormativo, sino porque el concepto de masculinidad asociado a la paternidad y la familia está condicionado por el estereotipo del padre como proveedor económico y modelo de hombría, de acuerdo con unos códigos de virilidad y de deseo heterosexuales. Por otra parte, la masculinidad se convierte en correlato de la transexualidad femenina a partir del reconocimiento de la homosocialidad como principio en torno al que se organiza la virilidad y se legitiman, a su vez, los actos de violencia transfóbica:

ADELA se transforma en AGNES. ADEI sale y aparecen.

ADRIÁN y ARIADNA.

ADRIÁN: ¡Puto chillón!

AGNES solloza intensamente.

ADRIÁN: No que muy fregón, defendiendo los derechos de los jotos y toda la bola de degenerados.

AGNES: ¿Qué quieres, Adrián?

ADRIÁN: ¡Qué te importa, maricón!

AGNES: Pensé que éramos novios.

ADRIÁN: ¡El marica eres tú, yo no!

ARIADNA: Fíjate que tu dizque novio también se tira a esta reinita.

ADRIÁN prende un cigarro.

ADRIÁN: Todos ustedes se sienten superiores a los demás. Ahí van por la calle pregonando sus consignas a diestra y siniestra. ¡Deberían de exterminarlos!

la autoridad propia de los hombres, son cobardes y maledicientes, y de ahí que se comporten como mujeres en las visitas, que cosan o que cojan en brazos a un perro faldero" (Josep Maria Sala Valldaura, "Gurruminos, petimetres...", p. 447).

23. Luis Bonino, "Varones, género y salud mental: deconstruyendo la 'normalidad' masculina", Nuevas masculinidades, p. 47.

24. Véase R. W. Connell, Masculinities, University of California, Berkeley, 1995. 
AGNES: Por favor, no me lastimen. [...]

ADRIÁN fuma con ira.

AGNES: ¿Por qué me dijiste que era una reunión de amigos?

ADRIÁN: ¡Para eso sí eres bueno: para el reventón!

AGNES: Adrián, ¿qué pasó?

ADRIÁN: No pasó nada.

AGNES: Dijiste que me querías.

ADRIÁN: ¡Y tú que te la crees!

AGNES: Por favor... No me lastimen...

ADRIÁN: Sabemos quién eres y estamos hasta el copete de sus discursos sobre la urgencia y necesidad de legislar a favor de la diversidad sexual. ¡Degenerado asqueroso! ¿Quién te crees que eres para exigir tus derechos! ¿En qué país crees que vives?

AGNES: En el mundo ${ }^{25}$.

Tal como señala Michael S. Kimmel, la homofobia es "el principio de organización central de nuestra definición cultural de masculinidad. Homofobia es más que el miedo irracional a los gays, es más que el miedo a que podamos ser percibidos como gay [...] es el miedo a que otros hombres nos desenmascaren, nos castren, revelen al mundo y a nosotros mismos que no alcanzamos los estándares, que no somos hombres de verdad" 26 . En la homofobia, reside no solo la exaltación de la virilidad, sino también el miedo a no recibir la aprobación "homosocial", a no ser reconocido como varón —y, por lo tanto, ser identificados dentro de los significados devaluados con los que se estereotipa la feminidad y se oprime a las mujeres_- Es decir, "la masculinidad está irremediablemente ligada a la sexualidad" ${ }^{27}$ porque su regulación contribuye al control y preeminencia de la heterosexualidad como norma de sociabilidad y deseo.

El término "transfobia", por su parte, hace referencia al miedo, aversión, odio, ira o indignación moral expresada hacia individuos que son percibidos como transgéneros o que no se corresponden con el binarismo de género socialmente construido (hombre/ mujer ${ }^{28}$. De acuerdo con esta idea, los perpetradores de crímenes de odio contra mujeres transexuales conciben que la flexibilidad de género socava la masculinidad hegemónica y los discursos que proyectan una deseada masculinidad, los cuales veneran las cualidades varoniles basadas en estereotipos del varón como un individuo carente de emoción, estoico y macho, lo que les lleva a justificar sus actos de violencia como una manera de reforzar su identidad. De allí que, como afirma, Joanna Jamel, "Cuando se deconstruye la violencia transfóbica, se hace explícita la complejidad más remota de la

25. Elena Guiochins, “Translúcid@”, pp. 265-266.

26. Michael S. Kimmel, "Masculinity as Homophobia. Fear, Shame and Silence in the Construction of Gender Identity", Theorizing Masculinities, eds. Harry Brod y Michael Kaufman, Sage, Thousand Oaks-London-Nueva Delhi, 1994, p. 131 (la traducción es mía).

27. Michael S. Kimmel, "Masculinity as Homophobia...”, p. 126 (la traducción es mía).

28. Joanna Jamel, Transphobic Hate Crime, Palgrave Macmillan, Cham, 2018, p. XI. 
naturaleza de esta violencia, esto es, la exacerbada influencia de la homofobia y del 'oneact rule' de la homosexualidad, la cual pareciera desestabilizar el significado de la propia orientación sexual y de la identidad de género del perpetrador masculino, significado que ha sido restringido y configurado por nociones hegemónicas y heterosexistas de masculinidad y virilidad" 29 .

La posibilidad de concebir la masculinidad como correlato de la transexualidad es, desde mi punto de vista, uno de los mayores aciertos de esta obra. Tanto porque nos permite condenar la sexualización de la feminidad, como porque nos lleva a comprender los modos de violencia que amenazan la supervivencia de las mujeres transexuales. Es en este contexto cuando la pregunta por la inteligibilidad cultural de los cuerpos transexuales que produce el passing entra en cuestionamiento y cuando la reflexión de Sandy Stone adquiere mayor relevancia: "Para deconstruir la necesidad de pasar, las transexuales deben responsabilizarse de toda su historia, empezar a rearticular sus vidas no como una serie de borraduras al servicio de una especie de feminismo concebido desde dentro del marco tradicional, sino como acción política empezando por la reapropiación de la diferencia y la recuperación del poder del cuerpo refigurado y reinscrito" 30 .

Lejos de ser divulgativa, la obra de Guiochins consigue que la representación y la performance escénicas exploren los límites de la inteligibilidad corporal para los sujetos trans, no solo en relación con la producción teatral, sino sobre todo de cara a las valoraciones normativas de lo que cuenta como humano y que determinan cuáles vidas cuentan como vidas y qué hace que una vida valga la pena ${ }^{31}$. De esta forma, si con Translúcid@asistimos a la reflexión acerca de las normas que "dominan la vida encarnada" y que nos atan y unen como humanos, urge entonces ampliar el espectro de interrogación y preguntarnos por cómo se conciben las vidas cuando se desafían estas normas. Es decir, es necesario dar un paso más y desafiar los modos de violencia y regulación que se ejercen sobre los cuerpos y las identidades y preguntarnos en qué medida el hecho de reproducir las condiciones de habitabilidad de lo que se entiende como vida amenaza la supervivencia de aquellos sujetos excluidos de la inteligibilidad del género y de las normas que garantizan la supervivencia social.

29. Ibid., 64 (la traducción es mía).

30. Sandy Stone, "El imperio contraataca. Un manifiesto postransexual”, pp. 61-62.

31. Véase Judith Butler, "La cuestión de la transformación social". 